\title{
Explanatory Models in the Processing of Science Text: The Role of Prior Knowledge Activation Through Small-Group Discussion
}

\author{
Henk G. Schmidt, Maurice L. De Volder, Willem S. De Grave, and Jos H. C. Moust \\ University of Limburg, The Netherlands \\ Vimla L. Patel \\ McGill University, Montreal, Quebec, Canada
}

\begin{abstract}
Two experiments assessed effects of activation of prior knowledge through small-group discussion. Subjects were given a description of natural phenomena and were asked to elaborate on possible explanations for them. In Experiment 1, small groups of subjects were presented with a problem describing the behavior of a blood cell in pure water and in a salt solution. No additional text was studied. The experimental subjects produced more than twice as many propositions about osmosis (i.e. the biological process explaining the blood cell's behavior) as a control group produced. Experiment 2 investigated effects of problem analysis on subsequent text processing for subjects with imprecise prior knowledge (novices) and subjects with precise knowledge (experts). Recall of the text showed considerable facilitative effects of problem analysis. Results are explained in terms of faster accessibility of prior knowledge and better integration of new information into explanatory models that may exist before, or are actively constructed during, problem analysis.
\end{abstract}

Attempts to understand the physical world involve the use of cognitive structures that represent mechanisms or principles underlying the phenomena observed. These cognitions may vary from highly sophisticated to quite naive. They may emerge as the result of formal education but often are constructed "spontaneously" while a person is experiencing the phenomena concerned.

Take thunder and lightning. By scientists, this natural phenomenon is interpreted in terms of large differences in electrical potential between clouds charged with static electricity and the earth. Young children however, generally favor explanations involving the clash of clouds, and in earlier centuries thunder was attributed to the rage of the gods. These naive "mental models" are, like the models of science, not merely descriptive of what is going on in the outer world. They are truly "explanatory," because they clarify why the world is as it is. In addition, these conceptions can be considered models because they usually consist of a set of concepts connected by causal links that help to interpret the phenomena concerned in terms of the underlying structure of these phenomena (Clement, 1979; Gentner \& Stevens, 1983).

This research was supported in part by a grant from the Faculty of Medicine of McGill University to Henk G. Schmidt while he was a visiting professor at that institution and by Grant 27798 from the Josiah Macy Jr. Foundation to Vimla L. Patel. Parts of it were presented at the annual meeting of the American Educational Research Association in Washington, DC in 1987.

We gratefully acknowledge the assistance of Bert Kerkhofs in the analyses of the data and the helpful comments of Lorence Coughlin, Steve Foster, and two anonymous reviewers.

Correspondence concerning this article should be addressed to Henk G. Schmidt, Department of Educational Development and Research, University of Limburg, P.O. Box 616, 6200 MD Maastricht, The Netherlands.
Research in the domain of science teaching has established the crucial role played by these existing cognitive structures in the comprehension of expository texts (Caramazza, McCloskey, \& Green, 1981; Champagne, Gunstone, \& Klopfer, 1983; Clement, 1982). In particular, when students' naive conceptions of natural phenomena deviate from scientific explanations, students have been reported to show serious difficulty in understanding the latter (Brumby, 1984; Green, McCloskey, \& Caramazza, 1980). One reason may be that in those cases, students are unable to relate what they already know about a subject to the new, discrepant information. In an early study on misconceptions in the domain of physics, for instance, Driver and Easley (1969) noted that high school students conversant with Newtonian mechanics nevertheless explained the movement of balls along a track by hypothesizing an "inner force" that pushed the balls forward. According to Newton, no force is exerted on a moving object (leaving friction aside). These students seem to have failed in integrating the new knowledge into existing structures in a way that would affect the old knowledge.

\section{Instructional Methods Aimed at Integration}

Several instructional approaches have attempted to deal with the problem of the integration of new knowledge into old. The literature suggests at least three distinct approaches.

The first is to encourage the person to produce elaborations on the basis of prior knowledge while processing new information. Examples of this approach are: asking students to answer questions about a text, to take notes, to write a summary, or to paraphrase the text (Bretzing \& Kulhavy, 1981; Glover, Plake, Roberts, Zimmer, \& Palmere, 1981; Hansen \& Pearson, 1983).

The second approach is to provide students with a description of a concrete model that can be considered an analogy 
of the concepts to be understood and that is formulated in terms of concepts familiar to the learner. Examples are descriptions of mechanical models, concrete advance organizers, and metaphors (Mayer \& Bromage, 1980; Royer \& Cable, 1976; Simons, 1984; Vosniadou \& Schommer, 1988). These analogies are considered to help in bridging the gap between what is already known and what should be learned, by acting as a frame into which the new concepts could be integrated.

More recently, a third approach has been suggested, namely, to encourage learners to construct an explanatory model by themselves on the basis of their prior knowledge. Typically, students are confronted with the description of a set of natural phenomena or witness an experiment. They are then asked to generate an explanation for the phenomena, or predict the outcome of the experiment (Inagaki \& Hatano, 1977; Smith, Johnson \& Johnson, 1981). Subsequently, they read an expository text on the subject, attend lectures about it, or see the actual result of the experiment. Champagne, Klopfer, and Gunstone (1982), for instance, describe an approach in which students are presented with qualitative mechanics problems, such as the following: "When a gun is fired, the bullet leaves the gun with some speed. How does the bullet's speed at the muzzle of the gun compare with the gun's speed at that time? How does the direction of the bullet's motion compare with the direction of the gun's motion?" Each student is required to produce a solution and then share his or her representation of the problem with the class. Subsequently, the teacher presents the physicist's analysis of the problem. It is suggested that thinking about a possible solution of the problem activates relevant prior knowledge that, in turn, facilitates the comprehension of the new information. The knowledge activated by this procedure would be represented as a causal model explaining the problem. To date, however, no empirical data are available to substantiate this claim.

In this article, a variation on the paradigm described by Champagne et al. (1982) is proposed-that is, using smallgroup discussion as the vehicle for the construction of an initial representation of the problem. Small groups of learners are given a description of a set of natural phenomena (e.g.: "A red blood cell is put into pure water under a microscope. The blood cell swells rapidly and eventually bursts. Another red blood cell is added to a solution of salt in water and is observed to shrink.") The learners are asked to explain these phenomena in terms of underlying processes, principles, or mechanisms. In other words, they are asked to construct an explanatory model using prior knowledge activated by the situation described by the problem (Barrows \& Tamblyn, 1980; Schmidt, 1982; Schmidt \& De Volder, 1984). It is only after the students discuss this problem and propose possible explanations that a text is presented that provides information relevant to the solution of the problem (in the case of the present example, a text on the osmotic process). The idea is that activation of relevant knowledge prior to the student's processing of a text would facilitate the integration of new concepts embedded in that text into existing cognitive structures.

In summary, it is assumed here that discussing a problem mobilizes relevant prior knowledge and thereby enables learn- ers to deal with the problem at some level of initial understanding. Second, the knowledge activated by the analysis of the problem will be "packaged" in a problem-specific explanatory model that takes into account the constraints of the task. (The task is to explain the phenomena in terms of an underlying process). Third, this model, constructed for understanding the problem, will facilitate the comprehension of new information relevant to the natural phenomena described.

This analysis leads to a number of questions of interest: (a) To what extent is prior, explanatory knowledge activated by small-group discussion of a problem? (b) Do students construct situation-specific explanatory models while they are representing a problem? (c) To what extent does discussing a problem before processing a relevant text support the acquisition of causal, explanatory concepts? (d) Does the possession of precise, as opposed to imprecise, prior knowledge differentially facilitate the construction of an initial representation and subsequent text processing? That is, will students with adequate prior knowledge for understanding a problem benefit more from the proposed procedure than those with inadequate knowledge or no specific knowledge?

This article reports on two experiments designed to investigate these issues. Experiment 1 was carried out to assess the extent to which analysis of a problem through small-group discussion activates previously acquired knowledge. To that end, small groups of subjects were presented with the blood cell problem. These subjects had studied the subject of osmosis pertaining to the explanation of the blood cell problem as part of their high school curriculum more than 2 years before Experiment 1 was carried out. In Experiment 1, they were required to recall everything they remembered about osmosis, and their performances were compared with those of subjects who analyzed a control problem prior to recall. Because the objective of Experiment 1 was to study the activation effect of problem analysis, no text was studied.'

In Experiment 2, effects of problem analysis on subsequent text processing were investigated. Subjects either analyzed the blood cell problem or a control problem prior to studying a text on osmosis. In order to investigate possible differential effects of amount of prior knowledge on subsequent recall, both subjects with imprecise prior knowledge (novices) and subjects with precise knowledge (experts) were involved in Experiment 2. In addition, verbatim transcriptions of the discussions were used to study the nature of the initial problem representations for both groups. It was assumed that these

\footnotetext{
'In this sense, Experiment 1 suggests a methodological elaboration of the "classical" instructional-aids approach, because, unlike in other research in this area, effects of the experimental treatment itself are the subject of investigation. Usually, effects of a certain manipulation (e.g., advance organizers or prequestions) are only investigated in conjunction with a text. In those cases, the effectiveness of the experimental treatment is assessed by comparing "treatment + text" with "control problem + text." In Experiment 1, however, effects of a "treatment-without-text" are studied. This approach enables the investigator to observe directly the kind of cognitive changes produced by the instructional aid and is designed to facilitate the understanding of a subsequent text.
} 
transcriptions would provide information on the extent to which subjects construct explanatory models specific to the problem at hand.

The major dependent variable in the analyses to follow is the number of propositions in free recall. A distinction is made between numbers of explanatory and descriptive propositions recalled. According to Mayer (1985), the number of explanatory propositions in free recall is a sensitive measure of depth of integration of subject matter into existing knowledge structures. Bromage and Mayer (1981), for instance, report a correlation of .59 between the number of explanatory propositions in the recall of a text and performance on a problem-solving test on which subjects had to apply knowledge acquired from that text. They suggest that the better problem solvers had constructed a representation of the information that was better integrated with their previous knowledge of the subject. The distinction between explanation and description appears to be relevant here, given that our subjects were requested to produce explanations for the phenomena described.

\section{Experiment 1}

The purpose of Experiment 1 was to assess the extent to which prior knowledge is activated through small-group discussion of a problem.

\section{Method}

Subjects. Subjects were 39 college students $(31$ women and 8 men). Average age was 19.4 years, with a standard deviation of 1.1. The subjects' academic background included biology, although it was not part of their present training. The subject matter to be activated, osmosis, had been part of a course given almost 2 years before Experiment 1 was carried out. The subjects were paid for their participation.

Materials. Materials consisted of a description of the red blood cell problem, a control problem, and a free recall test. The red blood cell problem was formulated as already described. The control problem was phrased as follows: "At Amsterdam airport, one can observe how airplanes, weighing several tons, take off apparently without trouble. How can this phenomenon be explained?"

The free recall test consisted of three blank pages and a front page containing the following instruction: "Write down everything you remember about the subject of osmosis. Write in full sentences and avoid abbreviations or drawings."

Procedure. The subjects were randomly assigned to either an experimental $(n=20)$ or a control condition $(n=19)$. Both the experimental and the control group were then subdivided into three small groups of about equal size. An experimenter was assigned to each of these groups. All subjects received written instructions, explaining in some detail what was expected of them. Appendix A contains the text of the instructions. (The example provided in the instructions-static electricity as an explanation for the thunderstorm phenomenon-is, of course, unrelated to the subject of osmosis.) The experimenter actively questioned subjects to check their understanding of the way they were to proceed with the experimental problem. The introduction took 5 to $10 \mathrm{~min}$. Subsequently, the subjects were given $15 \mathrm{~min}$ to formulate explanations for either the blood cell problem or the airplane problem. After reading the problem for about $1 \mathrm{~min}$, the subjects began to propose explanations. The experimenter acted as a chairperson, summarizing the different points of view at regular intervals. Recording the discussion verified that no information was provided from which the subjects could derive insights into the underlying mechanisms of either problem. Seventy-three percent of the contributions of the experimenters consisted of questions for clarification; the remaining remarks were summaries that used the same terminology as the subjects or encouraging sounds, such as "Uh huh." The experimenter was instructed to terminate the discussion if no further response was given to his question of whether somebody wished to add clarifications or explanations. The different groups used $8 \mathrm{~min}, 55 \mathrm{~s}$ on the average (range $=8 \mathrm{~min}, 35 \mathrm{~s}-9 \mathrm{~min}, 40 \mathrm{~s}$ ). On the average, subjects talked for about $87 \%$ of the time; there were only marginal differences between groups.

Subsequently, the free recall test on osmosis was administered to both the experimental and the control group.

Scoring. In the scoring process, the free recall protocols produced by the subjects were first parsed by two independent judges into subject-predicate units (or propositions), each expressing a single idea. The interrater agreement for this task was $92 \%$. The boundaries of two adjacent propositions can be found by identifying appropriate linguistic markers in the text: conjunctions, adverbs, relative pronouns, semicolons, and full stops. An example is provided by the following protocol (slashes mark boundaries):

Osmosis is the process/by which a greater concentration attracts water from a lesser concentration,/when these concentrations are separated by a semipermeable membrane./ The Greek word osmos means push./The aspiration of water molecules is realized by diffusion/(diffundere means to disperse)./

Similar results, using somewhat different criteria, are produced by applying procedures proposed by Winograd (1983) and Mayer (1985).

Next, each proposition was checked for accuracy. In addition, the propositions were categorized as either explanatory or descriptive. An explanatory proposition was defined as a statement that either characterizes a process or describes the conditions under which this process occurs. All other propositions were considered descriptive. The next sentence provides three examples of explanatory propositions: "If salt solutions at different sides of a semipermeable membrane have a different concentration,/water molecules will move through the membrane from the higher to the lower concentration, until equilibrium is restored." An example of a descriptive proposition is, "Osmosis occurs both in people and plants." Interrater agreement for this task was $79 \%$. Differences of opinion between judges were solved by discussion.

\section{Results and Discussion}

Table 1 displays the average number of correct propositions in the protocols of the subjects in Experiment 1.

Table 1

Average Number of Explanatory and Descriptive Propositions Produced in Experiment 1

\begin{tabular}{|c|c|c|c|c|c|c|}
\hline \multirow[b]{2}{*}{ Group } & \multicolumn{2}{|c|}{$\begin{array}{l}\text { Explana- } \\
\text { tions }\end{array}$} & \multicolumn{2}{|c|}{$\begin{array}{c}\text { Descrip- } \\
\text { tions }\end{array}$} & \multicolumn{2}{|c|}{ Total } \\
\hline & $M$ & $S D$ & $M$ & $S D$ & $M$ & $S D$ \\
\hline \multirow{2}{*}{$\begin{array}{l}\text { Problem-analysis } \\
\text { group }(n=20) \\
\text { Control group } \\
(n=19)\end{array}$} & 14.4 & 6.2 & 12.8 & 5.8 & 27.2 & 9,1 \\
\hline & 4.4 & 1.9 & 7.5 & 3.0 & 11.8 & 5.4 \\
\hline Total $(n=39)$ & 9.7 & 6.6 & 10.2 & 5.4 & 19.7 & 7.5 \\
\hline
\end{tabular}


A two-way analysis of variance (ANOVA) was carried out that used condition as a between-subjects variable and type of propositions produced as a within-subjects variable. Subjects who analyzed the blood cell problem produced significantly more propositions related to osmosis than did subjects in the control condition, $F(1,37)=31.06, M S_{\mathrm{e}}=36.49, p<$ .001 . This result suggests that problem analysis through smallgroup discussion is a strong activating medium of knowledge acquired at an earlier stage. (As has been indicated, subjects of both groups were taught about osmosis almost 2 years before the experiment was carried out). The problem-analysis group produced more than twice as many propositions as did the control group. It should be noted that it was not the presence or absence of an activating procedure per se that caused the effect, because prior knowledge of the control group had been activated as well by the instruction to write down everything remembered about osmosis. Therefore, the small-group discussion that was intended to explain the phenomena described in the blood cell problem must be held responsible for the differences observed.

No significant difference was found between the number of descriptive and the number of explanatory propositions produced, $F(1,37)=1.65, M S_{\mathrm{e}}=5.84, p<.21$. However, a significant interaction effect emerged between experimental manipulation and type of propositions produced, $F(1,37)=$ 19.27, $M S_{\mathrm{e}}=5.84, p<.001$. In addition, the experimental treatment affected both the number of descriptive propositions produced, $F(1,37)=12.32, M S_{\mathrm{e}}=21.58, p<.01$, and the number of explanations, $F(1,37)=47.24, M S_{c}=20.75$, $p<.001$.

These data appear to indicate that problem analysis through small-group discussion not only stimulates the activation of prior knowledge but is particularly effective in encouraging subjects to come up with explanatory statements. Given the task at hand (that is, to explain a natural phenomenon in terms of an underlying process), the subjects seemed to reconstruct their prior knowledge of osmosis into explanatory, causal networks of propositions. Causal networks are known to provide greater cognitive coherence, which in turn may account for the superior recall (Gentner \& Stevens, 1983).

\section{Experiment 2}

The results of Experiment 1 suggest that prior knowledge can be mobilized by problem analysis. Experiment 2 considers the question of whether problem analysis prior to the processing of a relevant text facilitates the comprehension of information from that text. Prior knowledge activation may be a necessary, but by no means a sufficient, condition for new learning. According to Van Dijk and Kintsch (1984), existing cognitive structures should interact with new information to allow for the development of new, or the modification of existing, structures. Subjects must relate the contents of the problem analysis to the contents of the text. If they fail to do so, differences between conditions in the recall of a problem-relevant text are not expected to be found.

As has been made clear in the introduction to this article, subjects who only have general world knowledge available for explaining natural phenomena, and whose world knowledge conflicts with scientific concepts, may be particularly likely to fail to relate what they already know to what they are learning. If these subjects' knowledge is simply insufficient to make any sense of a problem, facilitative effects of problem analysis are not to be expected. By contrast, subjects with sufficient knowledge to understand the problem would be expected to benefit more from the instructional procedure, because they have more knowledge available into which the new information can be integrated. Cook and Mayer (in Mayer, 1985) report data that appear to support this point of view. For the present experiment, the implication would be that problem analysis prior to text processing would be less effective for subjects without specific prior knowledge than for subjects with prior knowledge.

This analysis, however, contradicts the idea, expressed by some investigators, that making students aware of the limitations of their present knowledge for understanding new information is crucial to the occurrence of learning (Champagne, et al. 1982; Inagaki \& Hatano, 1977). As Anderson (1977) puts it, "My conjecture is that the likelihood of schema change is maximized when a person recognizes a difficulty in his current position and comes to see that the difficulty can be handled within a different schema" (p. 427). Because the knowledge of novices by definition is poor in comparison to that of more advanced students, the novices may more clearly experience discrepancies between their present state of understanding and the knowledge necessary to comprehend the problem in depth. Therefore, the analysis of a relevant problem prior to the processing of a text may have its greatest impact on them.

In order to test these conflicting hypotheses, both subjects with aspecific, general world knowledge (novices) and subjects with specific prior knowledge (experts) were exposed to the instructional method. The analysis suggested by the introduction to this article would predict that experts would benefit more from the analysis of a relevant problem prior to reading, because of the availability of relevant prior knowledge, whereas the analysis of Anderson and others would predict the reverse.

Until now, we have assumed that subjects, when faced with a problem, construct an explanatory model that fits the specific situation described and is based on prior knowledge. However, no direct evidence has been provided to substantiate this claim. Therefore, the second objective of Experiment 2 was to provide qualitative information in this respect. Verbatim transcriptions of the discussions were analyzed to provide insight into the nature of the explanations subjects give while analyzing the blood cell problem.

\section{Method}

Subjects. Subjects were 88 students from a Dutch secondary school: 46 ninth-grade students (18 boys and 28 girls) and 42 tenthgrade students ( 24 boys and 18 girls). Average age of the ninth-grade subjects was 14.91 years $(S D=0.59)$, the tenth-grade subjects were on the average 16.14 years old $(S D=0.52)$.

The ninth-grade students were unfamiliar with the biological subject that had to be studied as part of the experiment, although they had general biology knowledge, including global knowledge of the structure of cells. Consequently, they were considered novices. The 
tenth-grade subjects had finished the part of their biology course that included the subject under study; they were the "experts" in this experiment.

Subjects were randomly assigned to the conditions of the experiment; thus, four groups were created-experimental and control groups for both novices and experts.

Materials. Materials consisted of the two problem descriptions used in Experiment 1, a text and a free recall test.

The text consisted of a six-page, typewritten booklet containing about 2,200 words. It was entitled "Osmosis and Diffusion" and contained passages on diffusion, diffusion rate, permeability of cell membranes, osmosis, osmotic pressure, osmotic value, plant cell structure, turgor, and plasmolysis. No reference to osmosis in blood cells was made.

The free recall test consisted of three blank pages and a front page giving the following instruction: "Write down everything you remember about the text on osmosis and diffusion. Write in full sentences and avoid a telegram style or drawings."

Procedure. The procedure was similar to the one followed in Experiment 1. All subjects were, within their condition, randomly assigned to groups of 6 or 7 . The experimental subjects analyzed the blood cell problem, whereas the control groups analyzed the airplane problem. Average time used for discussion was $9 \mathrm{~min}, 10 \mathrm{~s}$ (range $=$ $\pm 1 \mathrm{~min}, 25 \mathrm{~s}$ ). No systematic differences between novices and experts or between treatments were found. On average, subjects talked for about $82 \%$ of the time, with only marginal differences between groups.

The text was studied for no longer than $20 \mathrm{~min}$. In addition, the subjects had to complete a short questionnaire unrelated to the experiment, to prevent carry-over effects.

Finally, the free recall test was administered without time limits.

Analysis. Scoring of the free recall protocols was carried out in ways similar to those in Experiment 1. Interrater agreement for parsing was $96 \%$. Interrater agreements for correctness/incorrectness of propositions was $88 \%$. Judgments on whether propositions were either explanatory or descriptive coincided in $89 \%$ of the cases. Data were analyzed by applying a three-way ANOVA with two betweensubjects variables (treatment and level of expertise) and one withinsubject variable (type of propositions recalled: explanatory vs. descriptive.)

The audiotapes of the discussions of the blood cell problem were transcribed and the protocols were screened for explanations.

\section{Results and Discussion}

Free recall. Table 2 summarizes the results of free recall for both the experimental and the control condition, and for the novices and experts.

The three-way ANOVA yielded the following results: A significant difference was found for the total number of propositions correctly recalled, $F(1,82)=6.15, M S_{\mathrm{e}}=116.69, p<$ .05 . As could be expected, experts produced significantly more accurate propositions than did novices, $F(1,82)=82.47, M S_{\mathrm{e}}$ $=116.69, p<.001$. The interaction effect between treatment and level of expertise was not significant, $F(1,82)=.01, p<$ .93. These results indicate that presenting subjects with the blood cell problem and instructing them to produce explanations for its behavior generally facilitates the processing and retrieval of a problem-relevant text. Although the difference between the experimental and the control group appears to be greater for the novices than for the experts, the absence of
Table 2

Average Number of Correct Propositions Recalled in Experiment 2

\begin{tabular}{|c|c|c|c|c|c|c|}
\hline \multirow[b]{2}{*}{ Type of proposition } & \multicolumn{3}{|c|}{$\begin{array}{l}\text { Blood cell } \\
\text { problem }\end{array}$} & \multicolumn{3}{|c|}{ Control problem } \\
\hline & $M$ & $S D$ & $n$ & $M$ & $S D$ & $n$ \\
\hline Novices' propositions & 26.0 & 12.4 & 22 & 18.5 & 6.6 & 24 \\
\hline Explanations & 19.5 & 9.9 & - & 13.7 & 6.5 & - \\
\hline Descriptions & 6.5 & 4.1 & - & 4.8 & 1.8 & - \\
\hline Experts' propositions & 53.4 & 25.7 & 21 & 48.2 & 15.6 & 21 \\
\hline Explanations & 41.8 & 18.3 & - & 32.5 & 11.5 & - \\
\hline Descriptions & 11.6 & 7.3 & - & 15.2 & 7.6 & - \\
\hline
\end{tabular}

an interaction effect between level of expertise and treatment does not directly support the idea expressed by Anderson (1977) and others that more learning takes place in subjects who experience a larger discrepancy between what they know and what there is to know about a topic. However, neither is the straightforward hypothesis that those who have more prior knowledge would benefit more from the activation procedure supported by the results of Experiment 2. Experts and novices alike seem to be influenced by the problem analysis prior to text processing.

Overall, significantly more explanatory propositions than descriptive propositions were recalled from the text, $F(1,82)$ $=179.16, M S_{\mathrm{e}}=65.41, p<.001$. More interesting than this main effect are the significant interactions between treatment and type of propositions recalled, $F(1,82)=7.77, M S_{c}=$ $65.41, p<.01$, and level of expertise and type of propositions recalled, $F(1,82)=20.47, M S_{\mathrm{e}}=65.41, p<.001 .^{2}$

As can be observed in Figure 1, the difference between treatment effects is much larger for explanations than for descriptions. For explanations, the difference between treatments was significant, $F(1,82)=4.73, M S_{\mathrm{e}}=254.93, p<$ .05 ; for descriptions, however, the difference was not significant, $F(1,82)=.18, M S_{\mathrm{e}}=54.40, p<.67$. These outcomes imply that the experimental effect as reflected in the recall was entifely due to the processing and retrieval of explanative information. Descriptive facts are not better remembered as a consequence of the analysis of the blood cell problem. This effect is stronger for the experts than it is for the novices, hence the interaction effect between level of expertise and type of propositions recalled.

These data unambiguously demonstrate that asking subjects to explain a set of natural phenomena in terms of their causal underlying processes induces subjects to pick up explanatory information from a text that pertains to these phenomena. The retention of descriptive facts, however, is not specifically supported by the instructional procedure. These results are in accordance with other studies that have used the explanation/description distinction in recall, notably Mayer and Cook's (1981) study on prose comprehension and problem solving and Peper and Mayer's (1978) note-taking research.

\footnotetext{
${ }^{2}$ The three-way interaction between treatment, level of expertise, and type of propositions recalled was not significant, $F(1,82)=1.32$, $M S_{\mathrm{e}}=65.41, p<.25$.
} 


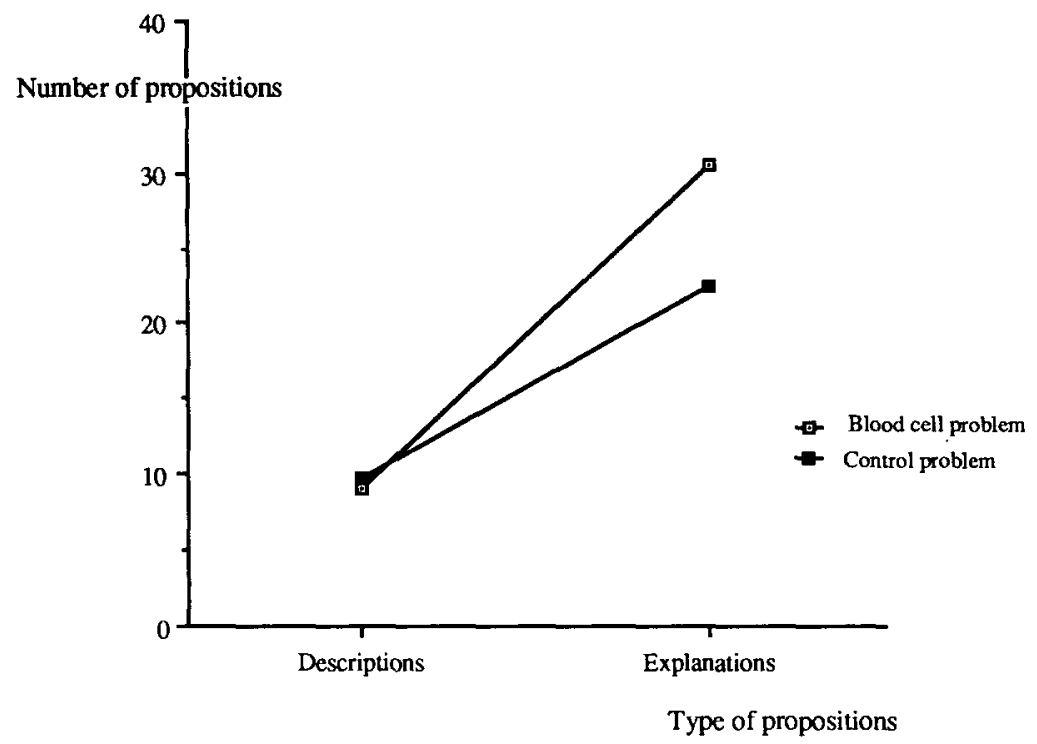

Figure 1. Average number of correct propositions recalled by experimental and control groups.

The question of course, is, Why is explanatory information better remembered under the conditions described in the present experiments? At least three answers are possible. The first is a motivational explanation. Subjects were confronted by a problem situation for which they had no satisfactory solutions. Berlyne (1978) suggested that whenever an individual perceives a discrepancy between what he or she knows about a subject and what there is to know, a cognitivemotivational process is triggered. This process, which Berlyne calls epistemic curiosity, is expressed in information-seeking behavior aimed at bridging the knowledge gap. However, an implication of this hypothesis would be that the expert group, which generally had no difficulty explaining why the blood cell swelled or shrunk, would experience less epistemic curiosity, and hence would show less gains than the novice group. This prediction, however, contradicts the outcomes of the present experiment, because no interaction effect was found between treatment and levels of expertise. In addition, this motivational hypothesis does not clarify why explanatory information in particular would be better remembered.

A second possibility is a selective attention explanation. Because subjects were asked to produce explanations for the behavior of the blood cell, they might have attended specifically to explanatory information in the text on osmosis and diffusion and might therefore have shown superior recall for that type of information. However, studies within the attentional framework have generally demonstrated that paying attention to specific parts of a text indeed results in superior recall of those parts, but at the expense of recall of parts that receive less attention (Goetz, Schallert, Reynolds, \& Radin, 1983; Rothkopf \& Billington, 1979). Thus, although this hypothesis may explain why the experimental groups showed superior recall of explanatory information, it fails to explain why the experimental group's recall of descriptive information was not poorer than the recall of the control groups as a result of the former's giving less attention to those elements of the text.

The third candidate for an answer is the activation hypothesis discussed in the introduction. According to this hypothesis, while trying to explain the phenomena described in the problem, subjects activate prior knowledge about the present or related subjects. Because of the constraints of the task, the knowledge activated will tend to be explanatory in nature. When the text is processed, the existing cognitive structures in which the information derived from the text has to be integrated will tend to be the previously activated explanatory knowledge, simply because this knowledge will be more easily accessed than will nonactivated descriptive knowledge. This would explain not only why more information is recalled from the text but also why explanatory information in particular is better remembered. In addition, explanatory knowledge is generally more coherent than are descriptive facts, because various propositions tend to be causally linked in memory, which may facilitate retrieval of those propositions in particular.

Verbatim transcriptions of the problem discussions. The purpose of Experiment 2 was dual: (1) to investigate the extent to which activation of prior knowledge through small-group discussion influences the comprehension of explanatory new information and (2) to provide qualitative information concerning the nature of the explanatory concepts used in the representation of the blood cell problem prior to the processing of the text. The question of interest with regard to the second issue was, In response to a problem, do subjects construct situation-specific explanatory models based on prior knowledge? An explanatory model was defined here as a set of concepts, connected by causal links, that provides an interpretation of observable phenomena in terms of their underlying structure (Clement, 1979; Gentner \& Stevens, 1983). 
In order to find an answer to the question at hand, the analyses of the blood cell problem conducted by the various experimental groups were transcribed. In the following discussion, transcriptions of the novices' discussions are emphasized, because the expert's groups came up with scientifically adequate explanations. ${ }^{3}$

A representative, verbatim excerpt illustrates the way in which explanatory models appear in the transcriptions. Those comments in italics represent an explanatory model, presented by Subject 2 (S2), that specified S2's view as to why the blood cell shrinks.

Experimenter (E): "Who wishes to say something about it? (silence for several seconds) It is difficult, isn't it?"

Subject 1 (S1): "The only thing I know is that there are two blood corpuscles, a red and a white one."

E: "Yes ..."

S1: "That was the only thing."

E: "And here the story is apparently about a red blood cell, one of the two. Could someone explain what happens to it?"

S2: "In salt it may dry up."

E: "Yes..."

S2: "That's why it shrinks"

S3: "Yes, you mean .........."

S2: "Salt withdraws ... eh ... withdraws liquids, because if you have a wine stain in the tablecloth, you immediately throw salt onto it, and then the salt absorbs it. So I think that in case of the blood corpuscle in the salt, the salt withdraws blood from the blood cell. That is why it shrinks."

The explanatory model displayed in this excerpt by $\mathbf{S} 2$ is based on a postulated hygroscopic property of salt, which causes blood to be withdrawn from the cell. According to S2, salt attracts liquids, and this property accounted, in his view, for the shrinking of the cell. This appears as Explanation 8 in Appendix B. Appendix B summarizes all the explanatory models found in the novices' discussions. None of the explanations occurred more than twice in different groups.

The information provided by Appendix B suggests that, while they discussed the problem, subjects indeed constructed explanatory models that fit the situation described in the problem and that were based on whatever prior knowledge and experience they could bring to that situation. Known objects, such as "sponges" or "valves"; processes, such as "corrosion" or "digestion"; and well-known attributes, such as the oxygen-carrying role of red blood cells, were combined into explanations unique to the particular problem situation. These familiar elements constituted the building blocks for the construction of mental models dealing with the new and unfamiliar situation. Activation of prior knowledge through small-group discussion not only mobilizes existing knowledge but appears to restructure this knowledge by creating new relations between concepts in a way that make sense to the persons who produce these relations.

A number of additional observations have been made by studying the transcriptions. First, novices dealt with the blood cell problem mainly by segmentation; that is, they showed a tendency to come up with separate explanations for each of the phenomena described. Only one group eventually produced an explanation that related the different phenomena (Explanation 12). Apparently, the problem had a level of complexity that could not be dealt with easily by the novices.
This contrasts with the solution strategies used by the experts, who explained the phenomena in relation to each other by one or two underlying principles. The causal explanations provided by novices appear to have a much more narrow application range than those of the experts. This finding is in accordance with findings in the domain of physics, where novices were also shown to be more cue dependent than experts in their responses to problems (Chi, Feltovich, \& Glaser, 1981).

Second, the novices predominantly seem to have searched for analogies that were based on surface characteristics of the problem (balloons inflated up to bursting or bodies floating in the sea) and to have applied them to the new situation. For instance, the swelling of the cell and the availability of water reminded them of the behavior of a sponge; therefore, they postulated little sponges within the cell (Explanation 1). In contrast, the experts postulated a not-directly-observable physical process underlying the problem and then attempted to explain the phenomena in the light of this process. They recognized the problem as a specific example of a more general principle and applied this principle to demonstrate that this was indeed the case.

Third, there was a general awareness among the novices that their models had only limited explanatory power, as witnessed by frequent remarks such as, "This doesn't explain the bursting."

Fourth, although the novices' explanations (for instance, the presence of "valves" in the cell's wall) contained elements useful to the understanding of the problems at hand, they were invariably incorrect. This suggests that it is not the extent to which previously held beliefs are correct that determines the extent to which learning will be facilitated, but rather the clash between new information and deficient knowledge of which the learner is aware.

\section{General Discussion}

The issue raised in the introduction to this article concerns the question of to what extent the acquisition of explanatory,

\footnotetext{
${ }^{3}$ For reference purposes, it may be useful to explain the osmotic process underlying the swelling, bursting, and shrinking phenomena described in the problem. The central mechanism involved is that of partial diffusion. If two solutions of salt in water are separated by a semipermeable membrane, the water molecules tend to move freely through the membrane, whereas the salt molecules cannot pass through. If concentrations on both sides differ, more water will flow from the smaller concentration to the larger concentration than vice versa, until both concentrations are equal. This can be understood at the molecule level by imagining a semipermeable membrane on which, at every moment and on both sides, 100 molecules bounce. If, on Side A, 80 water and 20 salt molecules bounce, and on Side B, 50 water and 50 salt molecules bounce, a net flow of 30 water molecules from $A$ to $B$ exists until both concentrations are equal. Therefore, if a blood cell with a concentration equivalent to $0.9 \%$ $\mathrm{NaCl}$ is put into pure water, osmosis takes place, and, because an equilibrium between concentrations cannot be attained, the cell eventually bursts. The shrinking of the blood cell is caused by osmosis of $\mathrm{H}_{2} \mathrm{O}$ from within the cell.
} 
causal knowledge about natural phenomena can be fostered by instruction.

In the experiments we conducted, subjects were asked to discuss a problem describing the behavior of a blood cell in two environments. The hypothesis was that asking subjects to explain these phenomena in terms of an underlying process would induce them to construct a mental model of what was happening to the blood cell and why that was happening. This explanatory model would be based on prior knowledge activated by the procedure and elaborated on by means of the discussion. The resulting cognitive structure would then facilitate the processing of a text on the subject (Schmidt, 1982).

The results of Experiment 1 suggest that problem analysis is an effective knowledge activation procedure. Subjects who analyzed the blood cell problem produced more than twice as many propositions when asked to write down everything they remembered about osmosis as did control subjects. The effect was particularly clear with respect to explanatory propositions in the recall: The experimental group produced more than three times as many of these. This outcome was attributed to the specific format of the activating procedure, which encourages subjects to reconstruct their existing knowledge on osmosis such that a more coherent "situation model" (Van Dijk \& Kintsch, 1984) is produced. This greater coherence may be responsible for the superior recall.

The outcomes of Experiment 2 indicate that analyzing a problem facilitates the subsequent processing of a relevant text. Overall differences in free recall between the experimental and control conditions were found. When the total number of propositions recalled was further analyzed into explanatory and descriptive propositions, it was demonstrated that the treatment had influenced only the recall of explanatory information from text. No differences were found for descriptions. This result was ascribed to a faster accessibility of explanatory information due to the activation task, which, in turn, would facilitate the assimilation of the new information. In addition, it was proposed that part of the effect may be caused by a greater coherence within causal propositional networks (Mayer, 1985).

Analysis of the transcriptions of the small-group discussions in Experiment 2 revealed that subjects did not just reproduce whatever they knew about the phenomena presented, but actively constructed causal models that fitted the specific problem at hand. In the process, they used known concepts or attributes and combined them into new structures. The novices tended to break down the problem into its constituent parts and to propose explanations for each of the phenomena separately, whereas the experts came up with one or two general underlying principles, of which the phenomena were considered to be just different manifestations. In addition, the novices made an extensive use of analogies that appear to have had certain manifestations in common with the phenomena described, or they applied well-known, but sometimes irrelevant, properties of the agents involved to explain the problem.

A somewhat surprising finding was that the novices' conceptions of the processes underlying the blood cell problem were not just imprecise or superficial, but simply wrong. This raises the question of how incorrect prior knowledge, if acti- vated, can nevertheless be helpful in mastering new information. An answer may be that to learn things that do not relate to, or are incompatible with, existing beliefs, the learner first has to become aware of his or her own perspective. Learning may be most effective if the learner is confronted with limitations in the explanatory power of his or her present conceptions of the world (Anderson, 1977; Piaget, 1954).

An issue not explicitly dealt with in this article is the extent to which group processes may have contributed to learning. Webb (1982) and Peterson and Swing (1985) for instance, have shown that providing explanations in response to questions by peers may be beneficial for both the provider and the recipient. This phenomenon may have played a role in the present experiments. De Grave et al. (1984) for instance, have found small but reliable differences between effects of individual and small-group problem analysis on text comprehension; these differences favor the latter. Because an informationprocessing, rather than a group-dynamics, perspective was adopted in the present experiments, questions regarding the influence of contributions of group members on the individual's problem representation are left unanswered.

In conclusion, the data presented suggest that activation of prior knowledge through small-group discussion of a problem can be a successful instructional strategy for bridging the gap between what is already known or can be inferred about a subject and new information to be learned. Learners, when confronted with a description of natural phenomena, actively construct explanatory models based on the prior knowledge they have about these or similar phenomena. The models constructed, in turn, facilitate the comprehension of an expository text relevant to the problem. These findings are explained by the better accessibility and greater cognitive coherence provided by the mental models that guide our understanding of the world and that ultimately dictate what we can learn about that world.

\section{References}

Anderson, R. C. (1977). The notion of schemata and the educational enterprise: General discussion of the conference. In R. C. Anderson, R. J. Spiro, \& W. E. Montague (Eds.), Schooling and the acquisition of knowledge. Hillsdale, NJ: Erlbaum.

Barrows, H. S., \& Tamblyn, R. M. (1980). Problem-based learning. New York: Springer.

Berlyne, D. E. (1978). Curiosity and learning. Motivation and Emotion, 2, 97-175.

Bretzing, B. H., \& Kulhavy, R. W. (1981). Note taking and passage style. Journal of Educational Psychology, 73, 242-250.

Bromage, B. K., \& Mayer, R. E. (1981). Relationship between what is remembered and creative problem-solving performance in science learning. Journal of Educational Psychology, 73, 451-461.

Brumby, M. N. (1984). Misconceptions about the concept of natural selection by medical biology students. Science Education, $68,493-$ 503.

Caramazza, A., McCloskey, M., \& Green, B. (1981). Naive beliefs in "sophisticated" subjects: Misconceptions about trajectories of objects. Cognition, 98, 117-123.

Champagne, A. B., Gunstone, R. F., \& Klopfer, L. E. (1983). Naive knowledge and science learning. Research in Science and Technological Education, 2, 173-187.

Champagne, A. B., Klopfer, L. E., \& Gunstone, R. F. (1982). Cog- 
nitive research and the design of science instruction. Educational Psychologist, 17, 31-53.

Chi, M. T. H., Feltovich, P. J., \& Glaser, R. (1981). Categorization and representation of physics problem by experts and novices. Cognitive Science, 5, 121-152.

Clement, J. (1979). Mapping a student's causal conceptions from a problem-solving protocol. In H. Lochhead \& J. Clement (Eds.), Cognitive process instruction (pp. 133-146). Hillsdale, N.J.: Franklin Institute Press.

Clement, J. (1982). Student's preconceptions in introductory mechanics. American Journal of Physics, 1, 66-71.

De Grave, W. S., Schmidt, H. G., Beliën, J. J., Moust, J. H. C., De Volder, M. L., \& Kerkhofs, L. M. M. (1984, April). Effecten van verschillende typen van activatie van voorkennis op recall, gemeten met een aanvultoets [Effects of different types of activation of prior knowledge on recall, measured with a completion procedure]. Paper presented at the Onderwijs Research Dagen, Tilburg, The Netherlands.

Driver, R., \& Easley, J. A. (1969). Autonomous dynamical thinking of young adolescent physics students. In J. A. Easley (Ed.), The use of mathematics in science teaching (pp. 117-142). Urbana: University of Illinois.

Gentner, D., \& Stevens, A. L. (1983). Mental models. Hillsdale, NJ: Erlbaum.

Glover, J. A., Plake, B. S., Roberts, B., Zimmer, J. W., \& Palmere, M. (1981). Distinctiveness of encoding: The effects of paraphrasing and drawing inferences on memory from prose. Journal of Educational Psychology, 73, 736-744.

Goetz, E. T., Schallert, D. L., Reynolds, R. E., \& Radin, D. I. (1983). Reading in perspective: What real cops and pretend burglars look for in a story. Journal of Educational Psychology, 75, 500-510.

Green, B., McCloskey, M., \& Caramazza, A. (1980). Curvilinear motion in the absence of external forces: Naive beliefs about the motion of objects. Science, 210, 1139-1141.

Hansen, J., \& Pearson, P. D. (1983). An instructional study: Improving the inferential comprehension of good and poor fourth-grade readers. Journal of Educational Psychology, 75, 821-829.

Inagaki, K., \& Hatano, G. (1977). Amplification of cognitive motivation and its effects on epistemic observation. American Educational Research Journal, 14, 485-491.

Mayer, R. E. (1985). Structural analysis of science prose: Can we increase problem-solving performance? In B. K. Britton \& J. B.
Black (Eds.), Understanding expository text (pp. 65-88). Hillsdale, NJ: Erlbaum.

Mayer, R. E., \& Bromage, B. K. (1980). Different recall protocols for technical texts due to advance organizers. Journal of Educational Psychology, 72, 209-225.

Mayer, R. E., \& Cook, L. K. (1981). Effects of shadowing on prose comprehension and problem-solving. Memory \& Cognition, 9 , 101-109.

Peper, R., \& Mayer, R. E. (1978). Note taking as a generative activity. Journal of Educational Psychology, 70, 514-522.

Peterson, P. L., \& Swing, S. R. (1985). Student's cognitions as mediators of the effectiveness of small-group learning. Journal of Educational Psychology, 77, 299-312.

Piaget, J. (1954). The construction of reality in the child. New York: Basic Books.

Rothkopf, E. Z., \& Billington, M. J. (1979). Goal guided learning for text: Inferring a descriptive processing model from inspection times and eye movements. Journal of Educational Psychology, 71, 310327.

Royer, J. M., \& Cable, G. W. (1976). Illustrations, analogies and facilitative transfer in prose learning. Journal of Educational Psychology, 68, 205-209.

Schmidt, H. G. (1982). Activation and restructuring of prior knowledge and their effects on text processing. In A. Flammer \& W. Kintsch (Eds.), Discourse processing (pp. 325-338). Amsterdam: North-Holland.

Schmidt, H. G., \& De Volder, M. L. (Eds.). (1984). Tutorials in problem-based learning. Assen, The Netherlands: Van Gorcum.

Simons, P. R. J. (1984). Instructing with analogies. Journal of Educational Psychology, 76, 513-527.

Smith, K., Johnson, D. W., \& Johnson, R. T. (1981). Can conflict be constructive? Controversy versus concurrence seeking in learning groups. Journal of Educational Psychology, 73, 651-663.

Van Dijk, T. A., \& Kintsch, W. (1984). Strategies of discourse comprehension. New York: Academic Press.

Vosniadou, S., \& Schommer, M. (1988). Explanatory analogies can help children acquire information from expository text. Journal of Educational Psychology, 80, 524-536.

Webb, N. M. (1982). Student interaction and learning in small groups. Review of Educational Research, 52, 421-445.

Winograd, T. (1983). Language as a cognitive process: Vol. 1. Syntax. Reading, MA: Addison-Wesley.

\section{Appendix A}

\section{Instruction to Subjects}

Within the context of this experiment, you will be asked, together with the other members of your group, to propose an explanation for a number of phenomena described in a problem. In order to help you understand the nature of the task, we will provide you with an example. Read the following description of a problem:

"It is a hot and humid day. Many ascending dust particles can be observed in the air. By the end of the afternoon, dark clouds are building up and the weather becomes even more sultry. Then, suddenly: Lightning in the far distance, followed by a thunderclap. Heavy rain. Explain these phenomena."

The phenomena, described in this problem, require an explanation. If you think about it for a while, you may come up with an explanation like this:

\begin{abstract}
"It's about a thunderstorm. The lightning you see is the result of electric charges of hundred thousands of volts jumping over from cloud to cloud or to the earth like 'sparks'. This jumping over is accompanied by a sound: the thunderclap. A thunderstorm emerges because during warm days, dust charged with static electricity ascends into higher strata by means of hot air (hot air namely ascends). The dust particles gather in clouds, which by that acquire an increasing higher electric charge. If the difference in potential between cloud or between clouds and the earth is sufficiently large, and the air is sufficiently humid (to facilitate conduction), a spark will jump over."
\end{abstract}

An explanation like this is, although accurate, somewhat superficial. More can be said about the problem, but we will not do that here. It is important that it has become clear 
which activity will be required from you: You will be presented with a problem and your task is to think of possible explanations for the phenomena described in that problem. If you do not immediately know an explanation, for instance, because you never have encountered the subject in school, you should try to come up with some ideas using common sense reasoning. You will see that in many cases you know more than you think!

\section{Appendix B}

\section{Novices' Models Explaining the Blood Cell's Behavior}

\section{Swelling}

1. Cell is filled with tiny sponges absorbing the water.

2. Cell takes in water by unidentified mechanism because wall is porous. However, wall contains valves that prevent the water from returning.

3. Red blood cells carry oxygen. Cell withdraws oxygen from water and swells.

4. Cell contains salts dissolved in liquid. Solution exerts pressure on wall larger than counterpressure exerted by pure water.

5. Intake of water triggers unknown chemical reaction in cell.

\section{Bursting}

6. Blood cells usually take in small amounts of liquids, because in the body there are many. In this particular case, there is only one cell, who has to take in too much water.

7. Animate objects only have a limited life-span.

\section{Shrinking}

8. Water or other liquids are withdrawn from the cell because of hygroscopic properties of salt.

9. Salt water exerts higher pressure on wall than contents of cell. leak.

10. Salt corrodes wall by affecting wall molecules. Cell begins to

11. Salt diffuses into cell and digests cell from within.

\section{Swelling and Shrinking in Combination}

12. Cell contains salt which withdraws water from environment because of hygroscopic properties. If water in environment contains higher concentration however, liquids will be withdrawn from cell.

Received April 14, 1987

Revision received April 21, 1989

Accepted June 4, 1989 